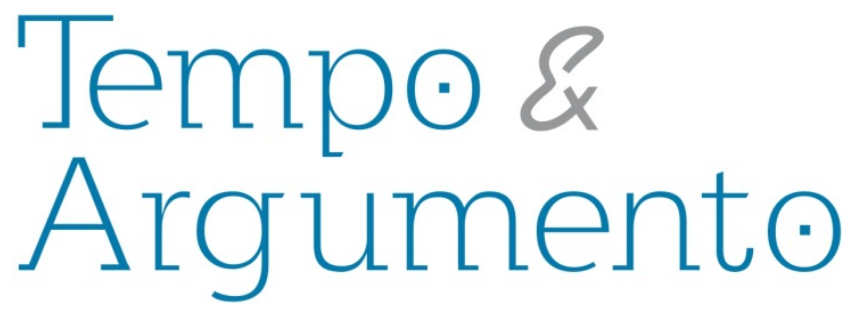

\title{
Cultura política e ditadura: um debate teórico e historiográfico
}

\section{Resumo}

O artigo tem o propósito de oferecer contribuições ao debate acerca da utilização da categoria cultura política em pesquisas na área de história. O texto está dividido em três partes, começando com uma discussão sobre as origens do conceito (proveniente das ciências sociais) e sua definição essencial. Logo em seguida, é apresentada uma proposta de análise visando a identificar os elementos constitutivos da cultura política brasileira, tendo a crise atual como horizonte. $\mathrm{Na}$ terceira parte, finalmente, são tecidos alguns comentários e explicações sobre o uso de cultura política em As universidades e regime militar. Cultura política brasileira e modernização autoritária, livro recentemente publicado pelo autor.

Palavras-chave: Ditadura. Historiografia. Cultura

Política. Modernização Autoritária. Universidades.

\section{Rodrigo Patto Sá Motta}

Doutor em História Econômica pela Universidade de São Paulo. Professor da Universidade Federal de Minas Gerais. Belo Horizonte - MG - BRASIL rodrigopsamotta@gmail.com

\section{Para citar este artigo:}

MOTTA, Rodrigo Patto Sá. Cultura política e ditadura: um debate teórico e historiográfico. Tempo e Argumento, Florianópolis, v. 10, n. 23, p. 109 -137, jan./mar. 2018. 


\title{
Political culture and dictatorship: a theoretical and historiographic debate
}

\begin{abstract}
The article intends to provide contributions to the debate on the use of the category of political culture in researches in the area of history. The text is divided in three parts, starting with a discussion about the origins of the concept (political culture) and its basic definition. Then we present a proposal for an analysis to identify the constituent elements of a brazilian political culture, taking into account the current political crisis. The third part, finally, consists on some comments and explanations about the use of political culture in the author's book "The universities and military regime. Brazilian political culture and authoritarian modernization".
\end{abstract}

Keywords: Dictatorship. Historiography. Political Culture. Authoritarian Modernization. Universities.

A proposta deste trabalho é discutir o conceito cultura política, que tem sido inspirador não apenas para reflexões acadêmicas, mas, também, para comentários jornalísticos ${ }^{1}$. Se a categoria cultura política vinha sendo utilizada de maneira crescente desde há alguns anos, especialmente devido ao impacto da renovação da história política e ao giro culturalista, a atual crise brasileira trouxe novos estímulos para pensar o país perscrutando tradições arraigadas e dilemas estruturais. Temos visto um movimento de retorno a temas clássicos do pensamento social brasileiro, em busca de inspiração para compreender o momento crítico. Em meio às tentativas de compreender o quadro presente e, quem sabe, encontrar algumas rotas de saída para os impasses, cultura política pode inspirar caminhos férteis.

\footnotetext{
${ }^{1}$ A exemplo de texto publicado recentemente na Folha de São Paulo por Otávio Frias Filho que, com base em rápida referência à cultura política brasileira, vaticinou o esvaziamento da candidatura Bolsonaro. Esperemos que tenha razão. Folha de São Paulo, 13/08/2017, caderno llustríssima.
} 
Para além de modismos e apropriações ligeiras, trata-se de categoria útil para pesquisadores de história recente e cientistas sociais, o que justifica os riscos e polêmicas inevitavelmente envolvidos, e estimula reflexões para sua utilização em bases teóricas mais sólidas. Sobretudo se conseguirmos superar os limites do ensaísmo, partindo de insights inteligentes na direção de pesquisas e referenciais empíricos que permitam, ou não, confirmá-los.

Tenho investido no tema pelo menos desde 1996, quando escrevi o primeiro artigo abordando esta categoria ${ }^{2}$. O produto mais recente destas reflexões é um livro sobre as relações entre a ditadura e as universidades, cuja fundamentação teórica, em parte, foi baseada no conceito cultura política ${ }^{3}$. Pois bem, esta apresentação é desdobramento de tais investimentos teóricos e empíricos, contendo algumas novas reflexões elaboradas após a publicação do livro, sob o impacto da crise político-institucional recente.

Este texto está dividido em três partes: primeiro, uma discussão sobre as origens do conceito e sua definição básica; na sequência, uma proposta de identificar os traços essenciais da cultura política brasileira tendo no horizonte a crise atual; no terceiro momento, apresentarei alguns comentários e explicações sobre o uso de cultura política no livro As universidades e regime militar. Para esta última parte, peço a compreensão do leitor caso exagere no tom auto referencial.

Comecemos, então, pelas origens, este ídolo da tribo dos historiadores de que não abrimos mão, apesar das críticas de François Simiand. Muitos historiadores no Brasil conhecem a contribuição da historiografia francesa, em especial de Serge Berstein e Jean François Sirinelli, mas, com frequência, se ignora que o conceito cultura política foi originalmente desenvolvido pelas ciências sociais norte-americanas, entre os anos 1950 e 1960. Na verdade, a inspiração teórica remota encontra-se em autores do século XIX, que já se interessavam pelos impactos de valores e comportamentos culturais sobre a política. No entanto, o desenvolvimento sistemático do conceito deu-se no contexto pós-

\footnotetext{
${ }^{2}$ Motta, Rodrigo P.S. O conceito de cultura política. Anais do X Encontro Regional da ANPUH-MG. Mariana, 1996, p. 83-91.

3 Motta, Rodrigo P.S. As universidades e o regime militar. Cultura política brasileira e modernização autoritária. Rio de Janeiro: Zahar, 2014.
} 
modelo superior ${ }^{5}$. Além disso, as culturas políticas eram pensadas em termos de espaço nacional (alemão, italiano, inglês etc.), provocando a tentação do etnocentrismo. Desde então tem havido debate acirrado nas ciências sociais, ainda inconcluso, sobre o potencial explicativo de cultura política, uma contenda que se mescla aos embates entre as vertentes institucionalistas e culturalistas (FORMISANO, 2001). Em que pesem as diatribes teóricas, o conceito trouxe contribuição importante ao estimular a pesquisa das interconexões entre política e cultura, enriquecendo os tradicionais paradigmas iluministas e racionalistas.

Os historiadores se apropriaram desta construção teórica das ciências sociais, notadamente a partir do "retorno" e da renovação da história política nos anos 1980 e 1990, mesmo período em que o giro culturalista se fez sentir nos meios historiográficos. Entre os franceses, destacaram-se, entre outros, Sirinelli e Berstein, cuja contribuição veio a se tornar muito conhecida no Brasil, talvez de maneira desproporcional. É certo que esses autores tiveram como ponto de partida a contribuição norte-americana, mas, ao contrário dos cientistas sociais dos Estado Unidos da América - muito influenciados pela sociologia e a psicologia -, o grupo francês teve como maior fonte de inspiração a antropologia, de cujo conceito de cultura se apropriaram. Eles sugeriram outra forma de conceber cultura política, partindo de duas críticas principais ao modelo norte-americano: primeiro, rejeitaram suas implicações etnocêntricas; segundo, consideraram inadequada a perspectiva nacional, tida como excessivamente generalista. Sua proposta é pensar a categoria em termos plurais, buscando identificar as diferentes culturas políticas que integram e disputam um mesmo espaço nacional. Nessa linha, privilegia-se o estudo das culturas políticas comunista, socialista, liberal, conservadora (tradicionalista), republicana, entre outras.

\footnotetext{
4 Formisano,2001; Kushnir \& Carneiro,1999.

${ }^{5} \mathrm{O}$ trabalho seminal foi o livro de Gabriel Almond e Sidney Verba. The Civic Culture. Political attitudes and democracy in five nations. Princeton: Princeton University Press, 1963.
} 
Em uma tentativa de contribuir para o debate, em 2009 publiquei um texto ${ }^{6}$ em que propus a superação da aparente dicotomia entre os dois modos de conceber cultura política, no singular e no plural. Em outras palavras, a proposta era evitar a contraposição polar entre a perspectiva nacional e a matriz pluralista. É possível admitir a existência de padrões culturais comuns a um povo, uma cultura política brasileira, por exemplo, que ao mesmo tempo convive com culturas ou subculturas em disputa no interior do espaço nacional, enquanto estas, apesar de suas divergências, podem carregar algumas características semelhantes.

A afirmação da relevância do fator cultural, entretanto, não implica imaginar que todos os integrantes do grupo se comportem de modo uniforme, como se fossem movidos por uma força atávica. Os sujeitos não são peças inertes diante de estruturas sociais perenes. O campo da política supõe o protagonismo de agentes que fazem escolhas: há sempre margem para a opção entre diferentes caminhos de ação. Assim, não há que supor oposição entre a influência de padrões culturais e o arbítrio dos agentes políticos. O argumento é que as escolhas podem sofrer a influência da cultura política, que oferece aos agentes alguns padrões de ação já inscritos nas tradições, mais atraentes e viáveis por terem gerado sucesso em ocasiões anteriores. Por outro lado, embora cultura política implique relações sociais, valores e imaginários estruturados, bem enraizados na sociedade, isso não significa a impossibilidade de mudança. Aliás, talvez a grande crise atual seja o começo de mudanças estruturais na cultura política. O ponto será retomado mais adiante.

Outro aspecto chave nas pesquisas sobre cultura política é o método comparativo, que pode ser enriquecido por enfoques atentos às conexões e circulações (de práticas, de ideias, de imaginários etc.). Fundamental reiterar a importância de estudar o fenômeno em dimensão comparativa, entendendo que a partir do contraste entre culturas políticas diversas poderemos perceber melhor suas características e peculiaridades, que ficam mais visíveis quando comparadas com outras realidades e tradições. Aliás, não é por outra razão que tais reflexões costumam interessar mais a

\footnotetext{
${ }^{6}$ MOTTA, Rodrigo P.S. Desafios e possibilidades na apropriação de cultura política pela historiografia. In: Motta, Rodrigo P.S. (org.) Culturas políticas na história: novos estudos. Belo Horizonte, Argvumentvm, 2009.
} 

DaMatta.

Com base nas contribuições tanto de cientistas sociais quanto de historiadores, no mesmo texto publicado em 2009 sugeri uma conceituação para cultura política: conjunto de valores, tradições, práticas e representações políticas, partilhado por determinado grupo humano, que expressa/constrói identidade coletiva e fornece leituras comuns do passado, assim como fornece inspiração para projetos políticos direcionados ao futuro. Creio que esta acepção confere mais densidade ao conceito, no entanto, existem outras possibilidades de conceituação. Há, por exemplo, quem utilize cultura política em sentido próximo a ideias políticas, ou mesmo a imaginários políticos. No entanto, corre-se o risco de reduzir o seu potencial analítico já que, nessas versões, não se levam em conta as práticas e ações políticas que, simultaneamente, expressam e ajudam a construir as culturas políticas. Nesses casos tratar-se-ia, talvez, mais de história cultural do político do que de pesquisas sobre culturas políticas na história. Mas, o debate segue aberto.

Com base em tais reflexões teóricas e conceituais, podemos avançar algumas tentativas de compreender questões estruturais da política brasileira, colocando em foco tradições arraigadas que reiteradamente nos interpelam, inclusive nos impasses atuais. Em que consistiria a cultura política brasileira? O debate sobre tais temas é tão antigo como o pensamento social brasileiro. Na verdade, mais antigo ainda, pois interessou aos viajantes estrangeiros do século XIX, embora o conceito cultura política seja de uso mais recente. Os precursores do debate foram ensaístas argutos cujas frequentes posições conservadoras não precisamos subscrever, ao contrário, a ideia é apropriar-se de algumas de suas formulações para compreender - e quem sabe transformar - as estruturas que mantêm as tradicionais desigualdades sociais do Brasil. Eles elaboraram insights interessantes para pensar a cultura brasileira, apontando tipos de comportamento que se enraizaram na tradição, com notável incidência política, como patrimonialismo, cordialidade, paternalismo, autoritarismo, personalismo, clientelismo, pragmatismo, além 
Antes de aprofundar a discussão sobre tais características, é necessário afirmar que a existência de cultura política implica um imaginário, neste caso, nacional, um conjunto de representações que contribui para instituir o grupo como comunidade política. Dessa construção fazem parte heróis, vilões, eventos marcantes, guerras etc., representações construídas por meio de imagens mentais ou visuais que são disseminadas, reproduzidas e reapropriadas ao longo do tempo, processo em que atuam tanto a memória como a historiografia, além da literatura, da cultura visual e das diferentes mídias. A questão do imaginário nacional (no caso brasileiro deve-se estar atento a particularidades regionais) tem sido explorada em bons trabalhos ${ }^{7}$, mas, é preciso ainda investigar mais. Não pretendo fazeê-lo aqui, mas apenas sugerir, pensando em futuras reflexões, que alguns quadros da pintura acadêmica do século XIX, que ajudaram a construir a imaginação histórica do país, convergem com alguns traços analisados a seguir, especialmente os temas da conciliação e da negação de conflitos ${ }^{8}$.

Voltando aos pontos elencados anteriormente que, como dito, integram a tradição do ensaísmo e, também, dos esforços das ciências sociais para identificar aspectos básicos da cultura brasileira, daremos mais atenção a dois temas: a conciliação/acomodação e o personalismo. No caso do personalismo, trata-se da primazia dos laços pessoais em detrimento de relações impessoais. De acordo com esta perspectiva, os brasileiros privilegiariam a fidelidade a laços de parentesco, de amizade, de compadrio ou de patronagem à revelia de normas universais, mostrando baixa adesão a projetos políticos e a instituições impessoais. Por isso, é mais frequente a identificação política com pessoas do que com projetos coletivos. Nesse sentido, o personalismo ${ }^{9}$ está

\footnotetext{
7 Por exemplo: Carvalho, José Murilo. A formação das almas: o imaginário da República no Brasil. São Paulo: Companhia das Letras, 1990.

8 Por exemplo, o quadro Independência ou Morte, de Pedro Américo, que é uma das imagens mais recorrentes nas representações políticas sobre o Brasil, e que retrata a conquista da liberdade nacional sem violência, a sugerir que a independência foi conquistada por um ato discursivo, o "grito" do Imperador.

9 Para uma análise do personalismo na cultura política brasileira na perspectiva da ciência política, ver Borba, 2005.
} 

termo conciliação já era usado desde o século XIX, celebrizado pelo acordo interpartidário que deu estabilidade ao segundo Império. O tema recebeu tratamento acadêmico em 1965, no livro de José Honório Rodrigues: Conciliação e reforma no Brasil: um desafio histórico-cultural, em parte inspirado pelo contexto da crise de 1964 e do golpe. Rodrigues pretendeu questionar os discursos sobre a "índole pacífica” dos brasileiros, ao mostrar que nossa história teve vários momentos cruentos. Porém, aceitou alguns aspectos das análises clássicas sobre o Brasil, falando em espírito de conciliação do povo "que se manifesta na mestiçagem, na tolerância racial e nas acomodações que atenuam os antagonismos sociais"10. Ao fim, concluiu que houve alternância entre momentos de conciliação e episódios de intensa violência, sendo maior a repressão quando os alvos eram os setores populares. E fixou um ponto importante: a conciliação foi uma estratégia dos grupos dominantes para construir estruturas de poder estáveis e para evitar rupturas revolucionárias.

Nos anos 1970 e 1980, outros autores voltaram a refletir sobre o tema, algumas vezes em viés mais crítico ou partindo de referenciais marxistas. Uma dessas incursões apareceu no ensaio de Antônio Cândido sobre o romance Memórias de um sargento de milícias. Cândido apontou naquela obra de Manuel Antônio de Almeida a representação de comportamentos sociais tipicamente brasileiros como tolerância, flexibilidade e disposição para acomodações, que serviriam aos setores populares como estratégias para lidar com a ordem, embora tenha questionado a ausência da escravidão no romance ${ }^{11}$. Alguns anos depois, no contexto das negociações para o fim da ditadura, Michel Debrun (1983) revisitou o tema da conciliação em viés propriamente político.

\footnotetext{
${ }^{10}$ Rodrigues, 1982, p. 33-34.

${ }^{11}$ Agradeço a Marcelo Ridenti por chamar minha atenção para este texto de Antônio Cândido (A dialética da malandragem), publicado em 1970. A menção ligeira ao texto de Cândido não significa desconhecer sua riqueza e complexidade, que não poderia abordar aqui. Por exemplo, em certos momentos ele pareceu atribuir tais comportamentos apenas às camadas intermediárias, e, em outros, ao conjunto da população. Para uma análise cuidadosa do ensaio ver Schwarz, Roberto. Pressupostos, salvo engano, de "dialética da malandragem".
} 
efeitos da mistura entre a cultura do colonizador e as culturas dos grupos africanos e indígenas, que geraram compromisso flexível entre as normas europeias e a resistência a elas oposta pelo contexto brasileiro; e outra conciliação, inextricavelmente ligada à primeira, mas, de natureza propriamente política, que fundamentaria a dominação com base em artifícios ideológicos (como o discurso sobre a cordialidade e o pacifismo do povo brasileiro).

Nos trabalhos de Rodrigues, de Antônio Cândido e de Debrun encontra-se o argumento de que as conciliações/acomodações envolvem as relações - e os conflitos entre raças e classes sociais. Presente, também, a ideia de que o fenômeno está imbricado aos processos de dominação, sendo que os autores oscilam entre considerar as conciliações como fruto de mero artifício ideológico ou como parte de construção social mais natural, resultado das circunstâncias de formação do país. Embora apontem o caráter arraigado de certas práticas e valores, parece que às vezes eles temeram ser acusados de reacionarismo e, talvez por isso, evitaram associar os fenômenos estudados à cultura ${ }^{12}$.

Pois bem, buscando inspiração nesses, e em outros autores clássicos, a proposta é entender como os choques e a integração entre europeus, africanos e indígenas que deram forma ao Brasil, e implicaram, naturalmente, a escravização e a dominação, incidiram na tradição de acomodações políticas. Fundamentalmente, trata-se de pensar como tais processos ajudaram a enformar uma cultura política, e de tentar superar a aparente polaridade entre cultura e ideologia, com base no entendimento de que esta pode estar subsumida naquela ${ }^{13}$.

Tal caminho analítico implica enfrentar um ponto polêmico: os efeitos da acomodação sobre os setores populares. Os grupos dirigentes buscam acordos para

\footnotetext{
12 “(...) embora a ideia seja à primeira vista bastante reacionária, sugerir a existência de arquétipos políticos brasileiros. Ou melhor, de arquétipos político-ideológicos, isto é, de formas permanentes de pensamento e ação política". Debrun, 1983, p. 17.

${ }^{13}$ Pretende-se aprofundar tal debate teórico em trabalhos futuros.
} 
até que ponto tais estratégias surtiram efeito e foram integradas à cultura popular. Em outras palavras, é possível que uma estratégia de natureza ideológica tenha se tornado cultura? Alguns elementos indicam resposta positiva, pois encontramos traços de acomodação no comportamento político de setores populares, seja aceitando - ou, ao menos, não se rebelando contra - sua exclusão política, seja adotando padrões de comportamento moderado, seja recusando apoio a propostas de mudanças radicais e preferindo soluções negociadas à opção de acirrar os conflitos.

A maioria dos autores a abordar a conciliação/acomodação percebem-na como uma estratégia de dominação enraizada no período colonial português, que foi mais desenvolvida sobretudo a partir da independência. A propósito, um processo sem ruptura aguda com Portugal, já que muitos laços com a antiga metrópole foram mantidos. Nesse sentido, a independência foi o primeiro grande episódio de acomodação, tendo como meta essencial manter o sistema de dominação e evitar rupturas sociais. Houve lutas e violência, inegavelmente, embora em menor escala quando comparamos com as independências dos outros países americanos. No final, prevaleceu um grande acordo, que ajudou a manter as estruturas sociais intocadas, especialmente a escravidão.

Tendo em vista a manutenção da ordem tradicional, a exclusão política dos setores populares era e é um objetivo permanente dos grupos dominantes, que para tanto usaram não apenas a repressão, mas estratégias de acomodação. As estratégias de controle social mesclaram episódios de violência extrema (como em algumas revoltas do período regencial e em Canudos) com medidas visando a integração subalterna dos grupos populares. Por aí se pode entender a política indigenista, que combinou paternalismo e assimilacionismo com violência (física e simbólica). Também pode se pensar, por meio desta chave, algumas políticas aplicadas à população negra: a elevada taxa de libertação de escravos e a integração dos negros como cidadãos de segunda classe no Império - que estabeleceu uma estratégia gradualista para acabar com a escravidão -, tudo isso conectado à intenção de desestimular ações radicais desses 
grupos dirigentes brasileiros no século XIX. Evitaram-se alguns conflitos internos às elites por medo de que processos de radicalização política pudessem mobilizar os escravos e destruir a ordem social. De maneira semelhante, do medo em relação ao potencial disruptivo dos conflitos raciais brotaram os tradicionais discursos sobre a harmonia e suposta democracia racial, um mito bem enraizado na cultura brasileira.

Arranjos de acomodação estiveram presentes não apenas no processo de Independência (com os portugueses, a quem pagamos - bizarramente - uma indenização), mas, também, na construção da unidade das ex-colônias (uma notável obra política baseada em violência e acordo), assim como em momentos seguintes, como no acordo partidário que fundamentou o segundo Império, e na criação da República sem participação popular de 1889. Nas décadas posteriores houve novas acomodações, como na ditadura Vargas, que, além de integrar intelectuais de esquerda ao aparelho do Estado, construiu legislação social visando afastar os trabalhadores de caminhos radicais e apagar da memória as anteriores lutas reivindicativas. Ocorreram situações de acomodação inclusive durante a última ditadura, e no seu final, o que permitiu uma transição pósautoritária suave para os agentes repressivos do Estado, que, até hoje, não foram julgados e, tampouco, punidos.

Embora o mais corrente seja usar a palavra conciliação, o termo acomodação ${ }^{14}$ pode ser mais adequado, pois permite expressar sentidos mais amplos. A conciliação na tradição brasileira significa o acordo político “pelo alto", envolvendo os grupos dirigentes e o Estado. Acomodação permite integrar este sentido e ampliá-lo, para incluir também arranjos em outros espaços sociais e institucionais, com envolvimento de outros atores, como intelectuais, acadêmicos e produtores culturais, e mesmo setores populares. Nem

\footnotetext{
${ }^{14}$ O termo acomodação foi utilizado tanto por José Honório Rodrigues como por Antônio Cândido, embora nem sempre com sentido político. Na época em que escrevi o livro ignorava o uso da mesma expressão em pesquisas sobre a dominação fascista na Europa dos anos 1940, especialmente nos trabalhos de Philippe Burrin (1995). Recentemente, analisei as diferenças no uso de acomodação para o caso da Europa sob domínio nazista e para o caso do Brasil da ditadura (Motta, 2016).
} 

lados, em um jogo de concessões mútuas. Para o jogo funcionar há que existir uma via de mão dupla, embora quase sempre se trate de situações de poder assimétricas.

Apresentado de maneira sumária, este quadro analítico/interpretativo implica debates polêmicos e, certamente, demanda aprofundamento nas pesquisas para ganhar mais solidez. Se o argumento estiver correto, a constituição desta cultura política ajuda a entender algumas características marcantes das nossas tradições: a costumeira desconfiança em relação às instituições políticas e o apego a lideranças carismáticas; a frágil adesão popular aos partidos e ao debate de ideias políticas; os baixos índices de participação política dos cidadãos, exclusão originada na escravidão e na barreira que por um século fechou a cidadania aos analfabetos; a frequente falta de confiança em ações políticas coletivas; o apreço por políticas gradualistas e a aversão a soluções radicais; as explosões intensas de participação ou de protesto popular (quebra-quebras, depredações, manifestações de rua), ao mesmo tempo superficiais e efêmeras. Trata-se de um quadro de tradições e valores políticos favorável a soluções "pelo alto" que excluem a maioria, possíveis devido ao alheamento político de muitos e a disposição favorável de outros tantos à acomodação. Pode-se argumentar que a auto exclusão política é também uma forma de sagacidade e de recusa consciente. Não se trata de ignorância política. Porém, esta forma de esperteza não resolve o problema, apenas facilita as coisas para quem controla o poder.

Primeira ressalva: não se trata de desvalorizar a história das lutas populares (lembrando que não abordamos a cultura em sentido amplo, apenas a política), que tem momentos marcantes de mobilização, notadamente quando estiveram em jogo demandas sociais ou culturais não conectadas diretamente a projetos políticos. A questão é evitar o exagero oposto, o superdimensionamento da história das mobilizações políticas populares, uma forma de idealização que serve para embalar sonhos e utopias generosas, mas, turva o entendimento e a ação. Tampouco se trata de subscrever os discursos tradicionais de que os brasileiros são pacíficos ou passivos. Na verdade, a 

acomodações e arranjos políticos excludentes da maioria.

Segunda ressalva: não se postula uma excepcionalidade brasileira, já que tais elementos são encontráveis em outras sociedades, notadamente o personalismo. 0 ponto é que a sua combinação aqui gerou um resultado peculiar e original. Última ressalva: abordar estas questões não implica voltar ao velho complexo de inferioridade; não é o caso de listar nossas mazelas e carências e lamentar a distância em relação às sociedades dos países centrais. Importante é perceber que esta cultura política teve um lado positivo também: a unificação do território da antiga América portuguesa, a construção de uma nação mais coesa do que seria de esperar (em vista das diferenças sociais e étnico-raciais), a capacidade de encontrar saídas políticas negociadas para alguns conflitos, o que, a depender da situação, pode representar o interesse da maioria. Sim, a disposição para aceitar negociações nem sempre traz resultados ruins. O nosso problema é pecar pelo excesso. Negociamos demais, acordamos demais e, com isso, postergamos a solução dos problemas. O medo do conflito provoca - e incrementa - o medo da mudança.

Aqui cabe refletir sobre os encontros entre a cultura política brasileira e as culturas de esquerda, como o comunismo e o petismo, que no último caso, principalmente, precisamos estudar mais, inclusive para entender o lugar ocupado pelo lulismo. Mesmo tais propostas de transformação social tenham acabado por se deixar influenciar pelas tradições políticas que pretendiam superar. Trata-se de armadilha difícil, pois, para transformar é preciso conquistar o poder e, para tanto, é necessário seduzir a maioria, o que leva à tentação - ou será uma necessidade? - de adotar mecanismos e comportamentos políticos tradicionais. Os projetos de esquerda que alcançaram popularidade no Brasil sempre se basearam em líderes com carisma forte e prestígio superior às instituições políticas, inclusive a seus partidos de origem: Brizola, Arraes, Prestes e Lula. Vários grupos de esquerda tentaram conquistar a sociedade brasileira, e alguns deles eram bem organizados, tinham bons líderes e intelectuais de prestígio. 
Trazendo a discussão para mais perto da crise atual, os governos liderados pelo Partido dos Trabalhadores (PT) aproximaram-se destes dois grandes traços da cultura política brasileira: o personalismo e a acomodação. Como foi dito, a estratégia da acomodação tem servido principalmente para preservar a ordem e evitar rupturas. Mas, também serviu a projetos de mudanças lentas, situação em que podemos enquadrar os governos petistas. O PT adaptou-se às tradições políticas e buscou acomodar-se com uma parcela dos grupos dominantes, para ser eleito e, também, para governar. Porém, ressalte-se: a versão “Lulinha paz e amor" serviu não apenas para reduzir a antipatia de setores da direita, mas, para seduzir segmentos populares que têm medo do radicalismo. O arranjo integrou grupos de direita e de centro ao governo de esquerda, e manteve aspectos negativos do sistema político. Porém, para chegar ao poder e realizar as almejadas mudanças sociais, ainda que de maneira lenta. Inegavelmente, os governos petistas impulsionaram parte da agenda de mudanças sociais, apesar do peso representado por alguns de seus sócios no poder.

O lulismo/petismo fez uso pragmático da acomodação. Apropriou-se de uma estratégia tradicionalmente conservadora e inverteu o seu sentido. O personalismo (encarnado em Lula) e a acomodação com setores de centro-direita permitiram eleger e reeleger dois presidentes de esquerda em um país onde ela é minoritária. É preciso reconhecer que, sem esses acordos, o PT dificilmente chegaria ao poder e certamente não teria conseguido um governo estável. Além disso, a estratégia de mudanças lentas é adequada em quadro de escasso apoio popular a projetos radicais. Um estudioso do lulismo argumentou que há uma camada importante da população pobre avessa ao radicalismo, preferindo mudanças lentas aos riscos dos confrontos agudos ${ }^{15}$.

Em grande medida, a acomodação promovida pelos governos liderados pelo PT derivou da falta de apoio popular para medidas mais agudas. Um exemplo são as políticas

\footnotetext{
${ }^{15}$ Singer, 2012. Estou de acordo, em linhas gerais, com a proposta analítica do autor, mas, desde que o tema seja pensado em duração mais longa, inscrevendo o que ele chama de lulismo em traços culturais mais gerais.
} 
da direita e a acomodação de alguns interessados, sob o pano de fundo do desinteresse popular, cortaram a viabilidade política da ideia. O mesmo pode ser dito dos planos para criar algum tipo de controle público sobre a grande mídia: o projeto foi abaixo após um coro violento de críticas, sem ter conseguido mobilizar apoio social que servisse de contraponto aos interesses das empresas de comunicação.

O problema maior do projeto petista foi ter-se acomodado demais. Faltou tentar (para valer) mudanças no sistema político para livrar-se da necessidade de aliados interessados apenas em explorar (literalmente) a máquina estatal. Melhor teria sido se os governos petistas não tivessem se acomodado tanto e procurado meios de alterar o sistema político, embora reconheçamos a dificuldade de fazê-lo devido às razões estruturais já apontadas. O preço foi demasiado elevado, como está claro hoje. Os ratos não apenas abandonaram o barco. Eles o colocaram a pique. Com isso, os próprios governos petistas contribuíram para a crise que desaguou no impeachment. A responsabilidade direta não é sua, óbvio. Responsáveis pelos golpes são os golpistas. Porém, estes se alimentam dos erros dos seus adversários. Está claro, por outro lado, que os ataques ao governo e o crescimento da direita devem-se também a ações positivas das administrações petistas. As políticas sociais e culturais orientadas por valores de esquerda atiçaram a reação direitista, que saiu a campo para criar uma crise capaz de derrubar o governo. Crises são também momentos de criatividade, às vezes abrindo oportunidade para rupturas. O momento atual pode ser o marco de uma nova cultura política? Voltaremos ao tema na conclusão.

Passemos, agora, ao terceiro tempo deste artigo, em que comentarei a utilização da categoria cultura política no livro As universidades e o regime militar (MOTTA, 2014), bem como a sua recepção crítica. A pesquisa realizada para o livro, entre os anos de 2005 e 2011, foi fundamental para o desenvolvimento das reflexões teóricas apresentadas há pouco. As fontes orais produzidas para a pesquisa, bem como os documentos oficiais coletados, inclusive nos acervos dos órgãos de informação e repressão, trouxeram muitas 

cultura política.

Até então, vinha utilizando o conceito apenas em sala de aula, em cursos oferecidos no Programa de Pós-Graduação em História da Universidade Federal de Minas Gerais, que desde 2000 criou uma linha de pesquisa dedicada a história e culturas políticas. Naquele momento, usava a categoria somente em sentido pluralista, interessado em refletir sobre algumas culturas de esquerda e de direita (comunismo e conservadorismo, sobretudo). Os rumos da pesquisa sobre as universidades e a ditadura levaram-me a repensar a possibilidade de uma cultura política nacional, embora em acepção diferente da formulação original de Almond \& Verba. A experiência internacional marcou também o novo olhar, tanto o estágio de um ano nos Estados Unidos (Universidade de Maryland, 2006-2007) quanto os cursos e investigações que comecei a empreender, no mesmo período, dedicados a comparar a ditadura brasileira com as congêneres do Cone Sul. Tal mirada comparativa, que apontou diferenças e semelhanças entre o Brasil e seus vizinhos, foi fundamental para a decisão de aplicar o conceito ao espaço nacional.

A aplicação da categoria cultura política permitiu compreender - assim me parece - alguns aspectos paradoxais da ditadura brasileira, como seu caráter simultaneamente conservador e modernizador, em especial no que se refere à sua política universitária, em que repressão e negociações caminharam juntas. Um dos argumentos do livro é que certos aspectos tradicionais do comportamento político se reproduziram durante o regime militar, notadamente a tendência à acomodação e às práticas personalistas. 0 ponto central da hipótese é que o impacto da cultura política brasileira contribui para explicar o caráter modernizador-autoritário do Estado durante o regime militar, inclusive em sua manifestação específica nas universidades.

A força das tradições culturais ajudaria a compreender, igualmente, as relações peculiares do aparato repressivo com os meios acadêmicos e intelectuais. Para além da repressão, que não pode ser minimizada, tais relações foram permeadas por jogos de 
casos de contratações de docentes com tal perfil mesmo na fase mais aguda da repressão. Houve arranjos também para retirar pessoas das prisões, para liberar passaportes retidos e para obter autorização de saída do país.

Tive o cuidado de evitar afirmações deterministas, ressaltando que as acomodações nem sempre funcionavam (a violência repressiva ocorria simultaneamente em outras situações) e que se tratava, no final, de escolhas. Além disso, argumentei que as ambiguidades da ditadura se deviam não apenas à influência da cultura, mas também ao pragmatismo, já que reduzir os níveis de repressão poderia trazer bons resultados ao Estado. No campo acadêmico, por exemplo, isso permitiu contar com o trabalho de profissionais talentosos, que contribuíram para o sucesso de iniciativas científicas e tecnológicas, além de reduzir tensões políticas. No entanto, mesmo assim as tradições culturais importam para a explicação do processo. A possibilidade de acomodar intelectuais de esquerda em uma ditadura anticomunista não é algo corriqueiro, e o fato de existirem precedentes em momentos anteriores, como na ditadura do Estado Novo, servia de estímulo para que a flexibilidade fosse admitida mais uma vez. Além disso, os arranjos foram possíveis por se tratar de cultura elitista e politicamente excludente, ou seja, era admissível manter alguns quadros de esquerda no mundo acadêmico (enquanto outros eram expurgados) e tolerar a circulação do próprio marxismo em algumas áreas porque os efeitos eram controláveis, restritos a espaços bem delimitados.

O argumento de que se tratou de algo peculiar e conectado às tradições nacionais se sustenta graças à mirada comparativa, já que a situação foi diferente nos países vizinhos $^{16}$. Outro ponto relevante para a discussão é que no livro conectei os jogos de acomodação durante a ditadura - que facilitaram a negociação de conflitos e a redução de tensões - com os acordos realizados para a transição. Por exemplo, o fato de a lei de anistia ter permitido o retorno da maioria dos expurgados do serviço público civil (entre

\footnotetext{
${ }^{16}$ Tendo em vista os resultados das pesquisas disponíveis, sabemos que a repressão nas universidades chilenas e argentinas foi pouco flexível e bem mais extensa. Cf. Fernandes (2016) e Rodríguez (2015).
} 
ditadura ocorreu também no plano da memória, haja vista a recente homenagem a Newton Sucupira com a nova plataforma de dados de pós-graduação da CAPES. Em pleno governo liderado pela esquerda, uma agência oficial não considerou problemático distinguir um professor que ocupou cargos importantes durante o regime autoritário ${ }^{17}$.

Pois bem, o livro tem merecido boa recepção no Brasil e no exterior, gerando muitas resenhas e estimulando a realização de novas pesquisas sobre o sistema universitário durante a ditadura. Não que tenha inaugurado o tema ${ }^{18}$, porém, o estudo do processo simultâneo de modernização e repressão das universidades operado pela ditadura, assim como a atenção para as relações complexas entre Estado e lideranças acadêmicas, pesquisa feita à base de novas fontes documentais, resultou em contribuição original, independentemente das opções teóricas. Algumas pesquisas mais recentes têm confirmado as análises desenvolvidas no livro, às vezes encontrando novas evidências que as ratificam (LAUX, 2015). O próprio capítulo do relatório da Comissão Nacional da Verdade relativo a universidades confirmou os resultados do livro, nele baseando-se amplamente.

A parte mais polêmica do trabalho, previsivelmente, é a mobilização do conceito cultura política. Muitos leitores e pesquisadores concordaram com a argumentação teórica, mas há divergências também. Aproveito a ocasião para comentar sinteticamente a recepção crítica e esclarecer alguns pontos. As críticas são parte da cultura acadêmica e cumprem papel positivo, contribuindo para refinar análises e apontar novos caminhos de pesquisa. Além disso, são um índice da repercussão dos trabalhos, revelando, às vezes, que eles causaram incômodo. Seria de esperar uma recepção mal-humorada, em certos setores, a trabalho que mostra a acomodação entre a ditadura e alguns intelectuais e professores de esquerda, embora o livro aponte as ambiguidades desse processo - que

\footnotetext{
${ }^{17}$ Pode-se argumentar, com razão, que Sucupira ofereceu contribuição útil ao país. Mesmo assim, deveria ter sido ao menos registrado oficialmente que a homenagem era feita apesar das ligações do professor com a ditadura.

18 Já existiam pesquisas importantes sobre as universidades na ditadura, especialmente de L. Antonio Cunha (1988). Além disso, Marcelo Ridenti já havia usado o termo acomodação para designar a estratégia da ditadura em relação aos intelectuais acadêmicos (Ridenti, 2003, p. 156).
} 
outros colegas entendem não caber à historiografia qualquer esforço analíticointerpretativo, apenas o papel tradicional de narrar.

No caso de certas objeções, talvez seja inútil contra-argumentar. Mas, para quem duvida do potencial explicativo de cultura política, pode-se responder que qualquer tentativa de análise no campo das ciências sociais e da história está sujeita a limites, não havendo provas cabais em nenhum caso. Provas e evidências podem ser apresentadas no que toca a eventos e processos, porém, sua interpretação e a construção de sentidos a partir deles seguem polêmicas. O fato de que metade dos 50 entrevistados para o livro relatou casos de acomodação na ditadura serve de prova de que tais práticas eram frequentes, porém, não necessariamente de que a explicação se deve à cultura política. 0 argumento teórico torna-se convincente à base de um raciocínio lógico que conecta os eventos da ditadura a episódios semelhantes ocorridos em momentos anteriores ou posteriores de nossa história, ao mesmo passo que aponta sua presumível ausência (ou fraca incidência) em regimes autoritários similares ao caso brasileiro.

Essas análises seguem polêmicas e o aprofundamento do debate teórico pode trazer mais luz, especialmente se as críticas forem fundamentadas (e não baseadas em leituras apressadas). Certas críticas ao livro vieram de um artigo que, na verdade, ataca a maior parte da historiografia sobre a ditadura, acusando vários trabalhos de inconsistência teórica ${ }^{19}$. O autor do texto em questão, o historiador Carlos Fico, colocouse em posição olímpica, distribuindo críticas a torto e a direito, como um mestre-escola rigoroso, e fazendo afirmações peremptórias com base em conhecimento frágil da discussão teórica pertinente. É audacioso, para dizer o mínimo, afirmar a fragilidade imanente do conceito cultura política sem conhecer a literatura teórica de referência. Tal afirmação foi feita com base somente em breve texto de Serge Berstein ${ }^{20}$ traduzido no Brasil, desconsiderando outros textos do historiador francês e, principalmente,

\footnotetext{
19 Fico, Carlos. Ditadura militar brasileira: aproximações teóricas e historiográficas. Revista Tempo e Argumento, Florianópolis, v. 9, n. 20, p. 05-74. jan./abr. 2017.

${ }^{20}$ BERSTEIN, Serge. Culturas políticas e historiografia. In: AZEVEDO, Cecília e outros. Cultura política, memória e historiografia. Rio de Janeiro: FGV, 2009
} 
Berstein $^{22}$ referiu-se às relações entre as culturas políticas e a cultura global de uma determinada sociedade, ou seja, não usou a expressão “cultura política global”. Pueril, também, a estratégia de escorar-se em autores mais gabaritados para criticar referências teóricas usadas no meu livro. Assim, Fico apoiou-se em Jessé de Souza para atacar a obra de Roberto DaMatta, que foi uma das fontes de inspiração para o conceito de acomodação apresentado no livro. Na verdade, apropriei-me apenas parcialmente de alguns insights de DaMatta ${ }^{23}$, por não concordar com todas as suas posições (jamais usei a expressão "jeitinho"), tendo buscado inspiração também em outros “clássicos" que, no entanto, foram poupados de críticas.

Não quero me estender demais ${ }^{24}$, por isso mencionarei apenas mais alguns pontos, para esclarecer o modelo teórico adotado no livro. Aspecto significativo é que ele parece não ter entendido certas passagens do texto, e com isso fez interpretações próprias e atribuiu-me equívocos que, na verdade, são seus. Por exemplo, parece não ter compreendido a distinção entre contradição e paradoxo ${ }^{25}$. Afirmei que a ditadura foi movida por impulsos contraditórios, provenientes de setores que tinham projetos diferentes, gerando resultados paradoxais. No sistema universitário, alguns grupos pressionavam por modernização, enquanto outros demandavam expurgos mais

${ }^{21}$ Op. cit. p.13

${ }^{22}$ BERSTEIN, Op.cit.

${ }^{23}$ Os insights referidos encontram-se em diferentes obras do autor, mas especialmente em DAMATTA, Roberto. A casa \& a rua. 5. ed. Rio de Janeiro: Rocco, 1997.

${ }^{24}$ Existem outras inconsistências e pontos frágeis no texto de Fico, mas evitei mencioná-las para não prolongar este artigo além do limite.

25 “Assim, a grande contradição - como não poderia deixar de ser, haja vista o subtítulo do livro de Rodrigo - estaria no 'paradoxo central do regime militar - a modernização autoritária-conservadora' (MOTTA, 2014, p. 293)". Ora, como o próprio Fico transcreveu, eu escrevi paradoxo central; "grande contradição" é expressão usada por ele. Em outra passagem, atribuiu-me um "equacionamento problemático no que tange à noção de paradoxo ou contradição". Fica a dúvida se o colega percebe a diferença entre os dois termos. Eis a passagem do livro em que comento a distinção entre contradição e paradoxo: "Vale a pena esclarecer o sentido aqui atribuído às palavras "contradição" e "paradoxo”. Contradição ocorre quando se observa incoerência entre palavras e ações do mesmo ator, ou quando se afirma e nega simultaneamente algo ou alguma coisa, adotando-se ao mesmo tempo rumos que se opõem ou se anulam. Já paradoxo é utilizado em duas acepções principais: no sentido de situação que contradiz as expectativas e de contradição aparente. No caso das políticas universitárias do regime militar, pode-se perceber a manifestação tanto de paradoxos quanto, efetivamente, de contradições, embora estas fossem menos comuns". (MOTTA, 2014, p. 288). 
militares. No entanto, mostrei também que a repressão motivada por impulsos conservadores foi instrumental para avançar a pauta modernizadora da ditadura, de maneira que o desejo de manter a ordem à base da repressão, às vezes abriu caminho para mudanças, sobretudo institucionais e tecnológicas.

Outro ponto em que se estabeleceu confusão envolve o significado de conservadorismo: “Rodrigo pressupõe que 'as utopias conservadoras' almejavam a ausência de mobilidade. Seria bastante difícil demonstrar que os militares, os empresários, os liberais conservadores, a classe média alta e demais setores que provavelmente comungam do que Rodrigo chama de utopias conservadoras não desejavam a mobilidade social". Primeiramente, não afirmei que os grupos conservadores não desejavam a mobilidade social, e sim a preservação da ordem e das tradições morais $^{26}$. Segundo, quando falei em utopias conservadoras queria dizer isso mesmo, não me referia genericamente aos grupos de direita apoiadores da ditadura, já que nem todos eram conservadores, obviamente. Os grupos conservadores, no sentido clássico da palavra, seriam, por exemplo, os católicos e os protestantes conservadores, cujas ideias eram partilhadas por alguns militares, proprietários rurais e também por uma parte dos setores médios ${ }^{27}$. "Provavelmente comungam" foi uma interpretação equivocada do colega.

Em outra crítica ao livro, afirmou que seria absurdo pensar que militares radicais pretenderiam expurgar do sistema acadêmico todos os suspeitos e indesejáveis. Entretanto, muitos operadores dos aparatos de repressão queriam isso mesmo, basta pesquisar os seus arquivos, e tinham inveja da repressão mais ampla realizada em ditaduras vizinhas. Não puderam fazê-lo devido aos jogos de acomodação que outros setores da ditadura promoviam, às vezes até mesmo lideranças militares e policiais. Outra

\footnotetext{
${ }^{26}$ A frase completa é: "No entanto, o sucesso das políticas modernizadoras colocava em xeque as utopias conservadoras, pois solapava as bases da sociedade tradicional ao promover a mobilidade social e urbana em ritmo acelerado". Motta, 2014, p. 289.

${ }^{27}$ Para o debate conceitual sobre conservadorismo conferir Manheim (1982) e Nisbet (1987).
} 
matava. Ou seja, as pessoas lançavam mão de tais recursos por saberem que tinham chances de sucesso. Não se passou o mesmo em outros países, pelo menos não com a mesma frequência. Na comparação com as ditaduras vizinhas, o expurgo de intelectuais e acadêmicos com perfil de esquerda no Brasil foi realmente menos drástico. Não se trata de dizer que acomodações só poderiam ocorrer aqui, como se fossem jabuticaba, mas de afirmar que foram mais frequentes, mais viáveis.

Pinçando uma frase do livro, Fico imaginou ter encontrado grave inconsistência no argumento teórico $^{28}$. A acomodação devia-se à heterogeneidade da base social de apoio da ditadura ou à cultura política? Respondo que se devia às duas coisas, pois não argumentei que a cultura política explicaria tudo, isso seria uma tolice. Não me ocorreria imaginar um único fator causal a explicar processos complexos, até porque a literatura de referência propõe a análise dos impactos da cultura política em combinação com outros fatores (FORMISANO, 2001, p,403). Por outro lado, foi ignorada a afirmação apresentada no livro de que a heterogeneidade dos apoiadores do regime autoritário devia-se também à tradição de $\operatorname{acordos}^{29}$, com a ditadura brasileira optando por acomodar interesses e demandas de vários grupos, no lugar de escolher caminhos mais lineares, porque isso era procedimento admissível em vista de experiências passadas.

Detenho-me aqui. Não tive a pretensão de construir um modelo teórico perfeito, apenas de propor algumas hipóteses para aprofundar um debate que, aliás, ganhou maior importância depois de 2014. De qualquer modo, as críticas comentadas aqui não demonstraram a impropriedade de utilizar cultura política e acomodação - que seria um

28 “'Como já se disse, a flexibilidade que permitiu tais estratégias de acomodação se devia, em parte, à heterogeneidade da base de apoio do regime militar, que contava com alas favoráveis à moderação no uso da violência. Entretanto, é importante também levar em consideração a influência da cultura política brasileira, marcada por tradicional tendência à conciliação e à acomodação (Motta, 2014, p.310-311)'. Parece-me que, nesse momento, o arcabouço teórico de As universidades e o regime militar inconsolidase: os jogos de acomodação decorrem da cultura política ou da heterogeneidade da base de apoio do regime militar?". Fico, 2017, p. 23.

29 "Elemento básico para compreender a natureza paradoxal do regime autoritário foi o influxo da cultura política brasileira. A própria tendência a acomodar no 'barco' do poder grupos diferentes, com projetos díspares e às vezes contraditórios, é parte da tradição política do país”. Motta, 2014, p. 291. 


\section{Considerações finais}

Cultura política não é panaceia, não explica tudo e não oferece saídas analíticas fáceis para lidar com problemas complexos. Entretanto, é relevante para entender comportamentos políticos e o peso de relações estruturais, constituindo categoria útil para os pesquisadores da história recente. As tradições preexistentes impactam as escolhas políticas e impõem certos limites aos agentes. Ainda assim, estes sempre fazem escolhas, portanto, a cultura política não é uma camisa de força. Metáfora melhor seria comparar cultura política a uma moldura, ou a um trilho.

Os fenômenos abordados aqui não se resumem à ideologia e implicam também a cultura, ou seja, foram integrados aos valores e práticas políticas de segmentos sociais expressivos. Alguns aspectos da cultura política têm conexão com estratégias ideológicas, já que fazem parte de processos de dominação e de manutenção da ordem. Entretanto, não basta denunciá-los como ideologia e esperar que sejam superados, pois, se a análise estiver correta $^{30}$, eles passaram a fazer parte da cultura e tornaram-se estruturais.

Um dos riscos desta linha de análise é sermos levados a pensar que nada muda, ou seja, a confundir o que seria um fenômeno estrutural com a camisa de força estruturalista. Não é a intenção. O conceito é atraente por identificar os aspectos de uma cultura que são mais resistentes à mudança, que reforçam a tradição. Porém, as análises não devem se prestar à conclusão quietista de que nada muda, ao contrário. O propósito é enfatizar a necessidade de mudança. No caso do Brasil, mudar para termos menos acomodação e mais ativismo, mais participação, inclusive uma vivência política mais

\footnotetext{
${ }^{30}$ Reitero a necessidade de refletir mais sobre as relações entre cultura política e ideologia, não há a pretensão de resolver tema tão complexo de uma penada. Um caminho fértil pode ser seguir as reflexões gramscianas, partindo do pressuposto que as relações entre os interesses econômico-sociais e os campos político e cultural não são lineares.
} 
De um ponto de vista otimista, nossa tradição de acomodações, de escamotear conflitos e de acordos "pelo alto", pode ter um lado positivo. Ela evitou alguns impasses e pode ter reduzido a violência política (não a social), além de ter contribuído para manter unido um país continental e marcado por grande diversidade. No entanto, o custo foi elevado, pois tal tradição ajudou a postergar o enfrentamento de problemas graves, como as desigualdades sociais e a exclusão da maioria da população da cidadania plena. Em uma palavra, tais tradições políticas dificultaram a superação efetiva do legado da escravidão. O balanço mostra um desequilíbrio, os poucos ganhos não compensam os óbices. Parece claro que as desigualdades estruturais brasileiras, de longe o nosso pior problema, persistem e não são alteradas devido ao sistema político elitista, que reproduz a exclusão da maioria. A precariedade da democracia política, um traço básico de nossa cultura, contribui para a dificuldade de transformar o quadro social.

Entretanto, em momentos críticos podem surgir novas configurações e rupturas. Mesmo que sejam estruturalmente arraigadas, as culturas políticas podem mudar. Sociedades como a italiana, a alemã, a portuguesa ou a espanhola já foram consideradas incapazes de abrigar instituições e valores liberal-democráticos. No entanto, transformaram-se após passarem por momentos políticos críticos. A mesma possibilidade está no nosso horizonte? Esta crise tem potencial para uma quebra de paradigmas no que toca aos comportamentos e valores políticos? Estamos presenciando a formação de uma cidadania mais envolvida com as lutas políticas, com maior índice de participação? Estará nascendo uma tradição política mais visceral, mais conflitiva? Menos tolerante com estratégias de acomodação?

Por vezes, parece que a resposta a tais perguntas é positiva, quando vemos o aumento no índice de participação política e a virulência do debate político subindo de tom. Nos últimos anos ocorreu notável processo de politização e virtual polarização da sociedade na linha esquerda/direita, com milhões de cidadãos abraçando opiniões fortes e engajando-se, inclusive em manifestações de rua. Além disso, temos o fenômeno 
pelos direitos humanos - atraiu até agora quase $20 \%$ do eleitorado, mostra o esgotamento das tradições conciliatórias e da cordialidade ${ }^{32}$.

No entanto, em outros momentos temos a impressão que os velhos padrões políticos continuam valendo. Um ponto relevante é que a possibilidade de novas acomodações está sempre no ar, pairando, com muitos agentes políticos apostando no acordo "pelo alto" como forma de superar a crise. E a acomodação persiste em outras esferas, por exemplo, nos casos de alguns quadros técnicos ou acadêmicos que se acomodam com o governo egresso do golpe, tal como ocorreu nas ditaduras dos anos 1930 e 1960. Quanto à força da tradição personalista, ela segue intocada. E vai ser mais importante ainda nas próximas eleições, devido ao esfacelamento dos partidos.

Além disso, a maioria da população continua a não se envolver nos embates políticos, mantêm-se à margem, excluída. Embora grupos numerosos estejam em ação, à esquerda e à direita, a maioria dos cidadãos continua fora do cenário. E, em muitos casos, a politização parece ser superficial. Certos traços estruturais continuam influentes, como as mobilizações intensas, porém efêmeras, seguidas de certo esgotamento político, tal como vimos em outros momentos históricos. Muitas pessoas cansam-se rapidamente dos embates políticos e passam a acompanhar os acontecimentos pela TV ou nas redes sociais.

Os protestos de rua de 2015 e 2016, mesmo tendo mobilizado massa humana importante, trouxeram ao espaço público parcela diminuta da população. Mais significativo ainda, conforme mostram algumas pesquisas, a maioria dos participantes

\footnotetext{
${ }^{31} \mathrm{Em}$ momentos anteriores tivemos fortes candidatos presidenciais de direita conservadora, como Plínio Salgado ( $8 \%$ de votos em 1955) ou Enéas Carneiro ( $7 \%$ de votos em 1994). No entanto, as pesquisas mostram que Bolsonaro poderá superar em muito o teto eleitoral de Salgado e Enéas, além de estar ganhando votos entre setores anteriormente moderados, o que revela o fenômeno da direitização de uma parte da opinião pública.

${ }^{32}$ Olhando o quadro recente por outro prisma, e enfocando cultura política pela matriz pluralista, estamos experimentando um vivo embate entre tradições rivais, com a cultura liberal ganhando espaço velozmente, ao passo que também cresce a influência dos valores conservadores, enquanto as culturas de esquerda parecem refluir, mas ainda lutam pelo terreno.
} 
sociais. Seria uma massa social desorganizada que desconfia das instituições, o que é compatível com os traços anteriormente descritos para a cultura política.

Segue, também, a dificuldade dos setores populares em conquistar uma cidadania mais efetiva, rompendo os limites da sua tradicional exclusão política. Não é o caso de defender um modelo revolucionário abstrato, que tais setores deveriam seguir por força de alguma metafísica, mas, de pensar em ações mais comezinhas, como impedir um impeachment golpista que implicou derrota para os interesses populares. Certo que houve protestos e algumas ações coletivas importantes, como greves, notadamente mais mobilizadoras quando estavam em questão interesses imediatos, como a defesa da manutenção das leis trabalhistas. Porém, são protestos ainda insuficientes para significar uma ruptura de paradigma, e para impedir que um governo direitista, ilegítimo sob qualquer ponto de vista, continue a desmantelar programas voltados para a maioria da população.

Enfim, não basta culpar os líderes por sua possível traição ou incompetência. E também não é suficiente culpar as manipulações da mídia e de outros segmentos da elite, embora estes problemas existam. A explicação para o nosso drama passa também por alguns impasses da cultura política, que é preciso enfrentar. E, quem sabe, superar.

\section{Bibliografia}

ALMOND, Gabriel; VERBA, Sidney. The civic culture: political attitudes and democracy in five nations. Princeton: Princeton University Press, 1963.

BERSTEIN, Serge (Org.). Les cultures politiques en France. Paris: Éditions du Seuil, 1999. 
BERSTEIN, Serge. La culture politique. In: RIOUX, Jean-Pierre; SIRINELLI, Jean-François (Orgs.). Por une histoire culturelle. Paris: Éditions du Seuil, 1997, p. 371-386.

BORBA, Julian. Cultura política, ideologia e comportamento eleitoral: alguns apontamentos teóricos sobre o caso brasileiro. Opinião Pública, Campinas, v. XI, n. 1, mar., p.147-168, 2005.

BURRIN, Philippe. La France à I'heure allemande: 1940-1944. Paris: Éditions du Seuil, 1995.

CARVALHO, José Murilo. A formação das almas: o imaginário da República no Brasil. São Paulo: Companhia das Letras, 1990.

CUNHA, Luiz Antonio. A universidade reformada: o golpe de 1964 e a modernização do ensino superior. Rio de Janeiro: Francisco Alves, 1988.

DAMATTA, Roberto. A casa \& a rua. 5. ed. Rio de Janeiro: Rocco, 1997.

DEBRUN, Michel. A “conciliação” e outras estratégias. São Paulo: Brasiliense, 1983.

DUTRA, Eliana de Freitas. História e culturas políticas: definições, usos, genealogias. Varia Historia. Belo Horizonte, n.28, p.13-28. 2001.

FALCON, Francisco. História e representação. In: CARDOSO, Ciro F.; MALERBA, Jurandir. Representações: contribuição a um debate transdisciplinar. Campinas: Papirus, 2000.

FERNANDES, Luan Vasconcelos. Professores universitários na mira das ditaduras: a repressão contra os docentes na UFMG (Brasil, 1964-1969) e na UTE (Chile, 1973-1981). 2016. Dissertação (Mestrado em História) - UFMG, 2016.

FICO, Carlos. Ditadura militar brasileira: aproximações teóricas e historiográficas. Revista Tempo e Argumento. Florianópolis, v. 9, n. 20, p. 05-74, jan./abr., 2017.

FORMISANO, Ronald P. The concept of political culture. Journal of Interdisciplinary History, v. 31, n. 3, p. 393-426, 2001.

FREYRE, Gilberto. Ordem e progresso. $1^{\circ}$ Tomo. Rio de Janeiro, José Olympio, 1959.

GINZBURG, Carlo. Relações de forçaistória, retórica, prova. São Paulo: Companhia das Letras, 2002.

GOMES, Angela de Castro. História, historiografia e cultura política no Brasil: algumas reflexões. In: SOIHET, Rachel; BICALHO, Maria Fernanda; GOUVÊA, Maria de Fátima 
(Orgs.) Culturas políticas: ensaios de história cultural, história política e ensino de história. Rio de Janeiro: Mauad, 2005.

HOLANDA, Sérgio Buarque de. Raízes do Brasil. 26. ed. São Paulo: Companhia das Letras, 1995.

KRISCHKE, Paulo. Cultura política e escolha racional na América Latina: interfaces nos estudos da democratização. BIB, Rio de Janeiro, n. 43, p.103-126, 1997.

KUSCHNIR, Karina; CARNEIRO, Leando Piquet. As dimensões subjetivas da política: cultura política e antropologia da política. Estudos Históricos, Rio de Janeiro, v.13, n.24, p.227-250, 1999.

LAUX, Paola N. A Comissão de Investigação Sumária do MEC nas fontes do acervo particular Tarso Dutra (1969). 2015. Trabalho de conclusão de curso apresentado ao departamento de história da UFRGS, 2015.

LIMA, Gabriel Amato de. Aula prática de Brasil: ditadura, estudantes universitários e o imaginário nacionalista no Projeto Rondon (1967-1985). 2015. Dissertação (Mestrado em História) - UFMG, 2015.

MANNHEIM, Karl. O significado do conservantismo. In: MANNHEIM Karl. Sociologia. São Paulo: Ática, 1982.

MELLO E SOUZA, Antônio Cândido. Dialética da malandragem. Revista do Instituto de Estudos Brasileiros, São Paulo, n. 8, 1970.

MOISÉS, José Álvaro. Cultura política, instituições e democracia. Lições da experiência brasileira. Revista Brasileira de Ciências Sociais. São Paulo, v.23, n. 66, p.11-43, 2008.

MOTTA, Rodrigo Patto Sá. O conceito de cultura política. In: ENCONTRO REGIONAL DA ANPUH-MG, X, Mariana, 1996. Anais..., 1996. p. 83-91.

MOTTA, Rodrigo Patto Sá. Desafios e possibilidades na apropriação de cultura política pela historiografia. In: MOTTA, Rodrigo P.S. (Orgs.). Culturas políticas na história: novos estudos. Belo Horizonte: Argvumentvm, 2009.

MOTTA, Rodrigo Patto Sá. As universidades e o regime militar: cultura política brasileira e modernização autoritária. Rio de Janeiro: Zahar, 2014.

MOTTA, Rodrigo Patto Sá. A estratégia de acomodação na ditadura brasileira e a influência da cultura política. Páginas, Universidad Nacional de Rosario, 2016. 
(1955/1964): uma análise a partir da trajetória de José Maria Alkmin. Tempos Históricos. v.21, p. 356-384, 2017.

PUTNAM, Robert. Comunidade e democracia: a experiência da Itália moderna. Rio de Janeiro: Fundação Getúlio Vargas, 1996.

RIDENTI, Marcelo. Cultura e política: os anos 1960/1970 e sua herança. In: FERREIRA, Jorge; DELGADO, Lucília de Almeida Neves (Orgs.). O Brasil republicano: o tempo da ditadura. Rio de Janeiro: Civilização Brasileira, 2003. (4 vol.).

RODRIGUES, José Honório. Conciliação e reforma no Brasil. Rio de Janeiro: Nova Fronteira, 1982.

RODRÍGUEZ, Laura G. Universidad, peronismo y dictadura (1973-1983). Buenos Aires, Prometeo, 2015.

SCHWARZ, Roberto. Pressupostos, salvo engano, de dialética da malandragem. Data. Disponível em: http://acd.ufrj.br/pacc/literaria/schwarz.html.

SINGER, André. Sentidos do lulismo: reforma gradual e pacto conservador. São Paulo: Companhia das Letras, 2012.

VIANNA, Francisco José de Oliveira. Instituições políticas brasileiras. São Paulo: José Olympio, 1949. 